\title{
Relações de Amizade e Prática de Jogos Online: Um Estudo Exploratório Com Adolescentes
}

\author{
Simone Chabudee Pylro*, Claudia Broetto Rossetti, \& Agnaldo Garcia \\ Universidade Federal do Espírito Santo, Vitória, Brasil
}

\begin{abstract}
RESUMO
Considerando o progresso tecnológico e a repercussão dos mesmos nos contatos sociais, o presente estudo investigou a relação entre a prática de jogos online e a amizade em um grupo de 110 estudantes do Ensino Médio de escolas públicas e privadas. Para tanto, elaborou-se e aplicou-se um questionário que abordou aspectos como contato e comunicação, intimidade e proximidade, satisfação, apoio social e compromisso. Os resultados indicaram que algumas características das relações de amizade em situações presenciais comparecem nas relações entre os jogadores no ambiente online, que a amizade no contexto do jogo online parece organizar-se em torno do apoio social, e que o tipo de apoio sofre variações em função da configuração do ambiente em que a amizade se desenvolve.
\end{abstract}

Palavras-chave: amizade; adolescência; relacionamento interpessoal; jogos online.

\section{ABSTRACT \\ Relations of Friendship and Online Games Practice: An Exploratory Study With Teenagers}

Considering the impact of technological progress on social contacts, this study investigated the relationship between the practice of online games and friendship among 110 high school students from public and private schools. We elaborated and applied a questionnaire that addressed issues such as contact and communication, intimacy and closeness, satisfaction, social support and commitment. The results indicated that some characteristics of friendship relations in face-to-face situations show up in the relations between players in the online environment, that friendship in the context of online gaming seems to be organized around social support, and that the kind of support changes depending on the configuration of the environment in which the friendship develops.

Keywords: friendship; adolescence; interpersonal relationship; online games.

Neste artigo pretende-se problematizar, a partir de um estudo exploratório, as possíveis relações entre a prática de jogos online e as relações de amizade entre um grupo de adolescentes, estudantes do Ensino Médio. Para tanto, entendemos ser necessário discutir aspectos gerais que envolvem o relacionamento interpessoal e, em específico, a amizade, dentro de um contexto da prática de jogos online.

Segundo Hinde (1997), empregamos o termo relacionamento para descrever a relação entre marido e esposa, pai e filho, professor e aluno, empregador e empregado, etc., em muitos contextos. Embora o uso da palavra relacionamento no discurso cotidiano seja recorrente, a diversidade e a complexidade do fenômeno envolvido tornam necessário definir precisamente o que diferencia um relacionamento inevitável de um arbitrário. Parece que a amizade se enquadra mais nesta última categoria, pois pode ser considerada "um relacionamento com um maior grau de liberdade, na escolha de amigos e na sua continuidade" (Garcia, 2005a, p. 15). Além do aspecto volitivo, Hinde (1997) refere-se à concepção de relacionamento enquanto um

\footnotetext{
Endereço para correspondência: Universidade Federal do Espírito Santo, Programa de Pós-Graduação em Psicologia, Av. Fernando Ferrari, 514, Cemuni VI, Campus de Goiabeiras, Vitória, ES, CEP 29075-910. E-mail: simone.chabudee@gmail.com.

Agradecemos a Herycksara Santos de Souza, aluna da graduação do curso de Psicologia da Universidade Federal do Espírito Santo, por suas colaborações na coleta e tabulação dos dados do referido estudo.
} 
conjunto de interações, em que a comunicação se destaca como um aspecto essencial dessa convivência.

O estudo desenvolvido por Garcia (2005a), a partir da análise de aproximadamente 100 artigos publicados em dois importantes periódicos internacionais específicos sobre relacionamento interpessoal, não só ratifica a importância da comunicação na análise do relacionamento, mas também nos chama a atenção para o contexto. Segundo o autor, o contexto representa uma série de fatores "ambientais, geográficos, ecológicos, sociais, culturais, econômicos, tecnológicos, entre outros" que poderão influenciar os relacionamentos. (Garcia, 2005a, p. 11).

Desse modo, é necessário considerar no estudo dos relacionamentos interpessoais alguns aspectos contextuais relevantes, em especial quando se pretende discutir o tema amizade - que se constitui em uma das possíveis maneiras de se estabelecerem vínculos; pois as mudanças nos padrões de relacionamento observadas na sociedade devem ser analisadas à luz das transformações históricas, culturais e tecnológicas. Assim, é coerente pensar que as referidas transformações podem estar na origem de novos contextos de amizades.

Um exemplo da relevância do contexto na análise dos relacionamentos são os avanços tecnológicos. Tal progresso pode gerar mudanças na forma como os contatos sociais se iniciam ou se mantêm, pois, com o desenvolvimento dos serviços de telefonia e informática e com o crescimento das comunidades virtuais, por exemplo, construiu-se um ambiente que propicia não só aumento no número de contatos, mas também maior intensidade e frequência na comunicação.

O resgate etimológico dos termos "amigo" e "amizade" apresenta um dado curioso e pode exemplificar algumas mudanças que se colocaram na promoção e manutenção dos contatos sociais após os avanços tecnológicos que ocorreram nas últimas décadas. Silva (2002) relata que tais palavras indicam "originalmente proximidade física e geográfica” (p. 26). Assim, os amigos estavam sempre por perto, na vizinhança. Porém, com os avanços iniciais da civilização, no que diz respeito aos meios de transporte, amigos passaram a se separar provisoriamente ou por longos intervalos de tempo e até mesmo para sempre. Tal situação gerava um afastamento desses amigos, dificultando ou mesmo impedindo o contato mais próximo. Contudo os avanços tecnológicos posteriores também trouxeram contribuições no que diz respeito à manutenção dos laços de amizade, como, por exemplo, tornar mais acessível a locomoção entre diferentes regiões (Silva, 2002).

Hoje, porém, tais avanços tecnológicos são ainda mais significativos e vão para além das facilidades de locomoção, de maneira que, na contemporaneidade se tem a possibilidade de manter não só contatos com amigos, cujas amizades foram constituídas pessoalmente e que, por alguma razão, sofreram um afastamento geográfico, mas também os chamados relacionamentos virtuais que, por vezes, configuram amizades entre pessoas que jamais tiveram algum tipo de proximidade física ou geográfica. Assim, nos relacionamentos online, mantém-se contato em tempo real com amigos que se encontram em diferentes localidades - que podem ser próximas ou distantes de sua residência.

Desse modo, a análise do uso de ferramentas, que estão acessíveis na Internet e que favorecem a constituição ou manutenção de vínculos, parece ser relevante, até porque "o acesso cada vez mais amplo à Internet, por exemplo, gera amizades online, cujas propriedades assim como sua relação com as amizades face a face, ainda precisam ser investigadas em maior profundidade" (Garcia, 2005a, p. 16). Além disso, há a necessidade de ressaltar o caráter dialético dos relacionamentos, uma vez que indivíduos, interações, grupos e sociedade se influenciam reciprocamente; além de também sofrerem influências da sociedade, da cultura e de seu ambiente físico (Pylro, 2007).

$\mathrm{O}$ relacionamento de amizade também envolve reciprocidade, influência e escolha, e em geral, a similaridade de gênero, etnia, religião, nível sociocultural e econômico ou a prática de atividades compartilhadas (Feld \& Carter, 1998; Garcia, 2006; Hinde, 1997; Laursen, 1996). Na caracterização da amizade é importante destacar que se trata de um tipo de relacionamento interpessoal construído a partir de bases históricas, sociais e culturais, implicando variações, e do qual emanam sentimentos de confiança e segurança (Enomoto, 1999), além de representarem status nos grupos aos quais pertencem (Hinde, 1997).

As amizades podem surgir a partir de atividades compartilhadas em diversos ambientes, como escola, trabalho, vizinhança, locais para atividades esportivas ou religiosas, entre outros (Garcia, 2006), e fazem parte de uma rede mais ampla de relacionamentos (Feld \& Carter, 1998). Entre as principais característi- 
cas da amizade destacam-se a informalidade, a pessoalidade, a voluntariedade, a ausência de sexualidade exacerbada (Auhagen, 1996); a similaridade, a afirmação mútua da identidade, as expectativas de confiança e de apoio (Hinde, 1997); o companheirismo e a interdependência de ambas as partes (Adams \& Plaut, 2003; Auhagen, 1996; French, Bae, Pidada, \& Lee, 2006; Hinde, 1997).

Outro aspecto interessante, ao se pensar o tema amizade, diz respeito às particularidades de um dado período do desenvolvimento. Tais especificidades podem referir-se à centralidade e à intensidade do contato com os amigos, assim como os contextos em que a rede de amizades é tecida. Assim, no que se refere à amizade durante a adolescência, o grupo de amigos assume um lugar de destaque na vida social, servindo de apoio nas mais variadas situações, podendo representar fonte diferenciada de amparo em condições adversas, como no caso das enfermidades (Greco, Pendley, McDonell, \& Reeves, 2001; Ferreira \& Garcia, 2008).

Desse modo, os estudos sobre as redes de amizade podem ter como pano de fundo diferentes contextos dependendo da fase do desenvolvimento que se pretende investigar. No caso das crianças e dos adolescentes, os estudos geralmente estão relacionados ao ambiente escolar, ainda que seja possível encontrar discussões sobre como tais redes se constituem em vários outros ambientes (Ray, Cohen, \& Secrist, 1995).

Porém, independentemente da etapa de desenvolvimento ou da idade, há alguns aspectos mais gerais que comparecem nas relações de amizade. Assim, estas se caracterizam pela presença de busca mútua de ajuda, de companheirismo e de intimidade, de modo que amigos compartilham experiências e vivenciam conflitos (Berndt, 1992; Laursen, 1996). É curioso observar que o nível de intimidade também vai influenciar o conteúdo e as ações relacionais. Um exemplo é o fato de que amigos competem mais acirradamente em jogos competitivos que não amigos (Fonzi, Schneider, Tani, \& Tomada, 1997).

Ainda sobre esses aspectos mais gerais da amizade, também é importante destacar que o nível de intimidade, companheirismo e confiança está diretamente relacionado ao lugar que os amigos ocupam entre os demais companheiros, de maneira que as amizades são passíveis de serem classificadas em função desses fatores. Assim, é muito comum que entre os amigos, existam aqueles que recebem o título de melhores amigos (Azmitia, Lippman, \& Ittel, 1999), e aqueles que, apesar de serem amigos, não partilham esse mesmo nível de profundidade no relacionamento.

Diferenças culturais também podem influenciar a forma e a intensidade com que o apoio social é disponibilizado por amigos. Tal fenômeno ocorre com maior frequência em alguns países, em especial no Ocidente. Contudo, apesar dessas diferenças, amigos são, em geral, fontes significativas de intimidade e de companheirismo (French, Rianasari, Pidada, Nelwan, \& Buhrmester, 2001).

Apesar da presença de alguns fatores mais gerais na caracterização da amizade, verificam-se também algumas diferenças entre as meninas e os meninos. Há indícios de que as meninas mantêm um número menor de amizades do que os meninos, sendo que as amizades mais prolongadas estão vinculadas ao contexto escolar. Entre os temas utilizados para a caracterização da amizade, evidencia-se por parte das adolescentes uma tendência à exposição de questões pessoais e uma grande valorização do hábito de conversar entre si (Silva, Schoen-Ferreira, Medeiros, Aznar-Farias, \& Pedromônico, 2004). Este último aspecto - conversar com os amigos - parece continuar ocupando lugar de importância na caracterização da relação de amizade na vida adulta (Pylro, 2004; Pylro \& Rossetti, 2005).

De maneira geral, os adolescentes parecem constituir relações de amizade para satisfazer as necessidades prementes de intimidade, de autovalidação e de companheirismo, tão características dessa etapa do desenvolvimento (Buhrmester, 1996 citado por Wolak, Kimberly, Mitchell, \& Finkelhor, 2003). Porém, ainda que essa vocação para se relacionar se coloque como imperiosa e comum nessa fase da vida, é importante entender que os relacionamentos se configuram a partir de múltiplos fatores que os impactam e que podem eliciar a abertura de novas dimensões para as relações de amizade, de modo que alterações na estrutura familiar (famílias menores), maiores índices de escolarização e urbanização, o crescimento da inserção da mulher no mercado de trabalho e a convivência cada vez mais precoce da criança com seus pares em instituições sociais (desde as creches e escolas de educação infantil) resultam em uma maior intensidade e diversidade de contatos com estranhos, desde a infância, abrindo novas possibilidades e facili- 
tando a formação de amizades (Garcia, 2005b, p. 291).

Entre os temas investigados nas pesquisas sobre as redes de amizade, é possível encontrar estudos ressaltando as transformações tecnológicas e o impacto dessas mudanças na caracterização dessas redes (Griffiths, 1997). Assim, as transformações e os avanços que ocorreram nos últimos anos no que diz respeito ao universo online deram origem a um novo fenômeno: os relacionamentos online, que têm feito parte da cultura adolescente (Wolak e cols., 2003), e que têm chamado a atenção de estudiosos para seus possíveis significados e perigos durante esta fase da vida (Turkle, 1995, Freeman-Longo, 2000, citado por Wolak e cols., 2003).

Entre os ambientes disponíveis para o estabelecimento de relacionamentos interpessoais, via Internet, queremos destacar os jogos eletrônicos online - jogos praticados por meio de um terminal de computador ou console de videogame, que podem ser jogados individualmente (singleplayer) ou com outros jogadores (multiplayer) que não estão necessariamente em um mesmo espaço físico. Tais jogos podem contar com ferramentas próprias que viabilizam a comunicação durante as partidas (como o teamspeak), ou os jogadores comunicam-se por meio de outros recursos, como, por exemplo, o envio de mensagens instantâneas (como o Messenger - MSN). Essas ferramentas evidenciam que ao longo dos últimos anos, mudanças progressivas propiciaram a incorporação de novas tecnologias e suas aplicações no mercado da comunicação e do entretenimento, influenciando também novas configurações de relacionamento.

Esse contato com o computador e com os serviços decorrentes de seu uso tem-se ampliado e intensificado no cenário brasileiro. A cada ano observa-se um aumento no número de domicílios com acesso à internet, de maneira que, em 2008, 17,95 milhões de domicílios brasileiros $(31,2 \%)$ possuíam, pelo menos, um microcomputador, sendo 13,7 milhões $(23,8 \%)$ com acesso à internet (Instituto Brasileiro de Geografia e Estatística, 2009). Além da sua utilização em espaços mais privativos como os domicílios, o computador também vem sendo muito utilizado em ambientes públicos, seja em contextos de trabalho, seja no de entretenimento. No que se refere a este último, a partir de 2001, vivenciamos o surgimento, no Brasil, das chamadas lan houses - Local Area Network (locais equipados com computadores ligados em rede e com acesso à Internet, destinados principalmente à prática de atividades de entretenimento). Tais estabelecimentos permitem o acesso de multiusuários que podem comunicar-se entre si. Porém o contato pode não ficar restrito aos usuários presentes na lan house; de modo que usuários situados em diferentes espaços podem interagir, por exemplo, a partir de um determinado jogo (Alves, 2005). Portanto, nas lan houses, uma das atividades possíveis é a prática de jogos eletrônicos online, que podem se colocar como mais um ambiente possível para o estabelecimento de relacionamentos, inclusive de amizade; até porque entre as motivações presentes para se jogar, é possível apontar motivações sociais. Tal apontamento aparece ratificado em um estudo comparativo entre adolescentes e adultos sobre jogos computadorizados online (Griffiths, Davies, \& Chappell, 2004), em que se verificou que os adolescentes elegeram como características favoritas para jogar online quesitos sociais, como, por exemplo, ser capaz de ajudar os outros, ser um membro do clã, etc.

Assim, a Internet configura-se como um recurso de comunicação e ambiente relacional de grande importância para a vida social do grupo, e parece ter gerado uma revolução na sociabilidade: "parece ser a geração de novos complexos de comunicação e relacionamento, em que aspectos online ou offline da comunicação e do relacionamento estão dialeticamente relacionados, construindo-se mutuamente" (Pylro, 2007, p. 112). Evidentemente, as consequências decorrentes dessas práticas ainda não estão claras. Muitas são as especulações positivas e negativas. Singer e Singer (2007) relatam experiências interessantes, como a considerável contribuição dos jogos de computadores no desenvolvimento de habilidades imaginativas. Mas também apontam experiências que retratam a prática recorrente de jogos eletrônicos como perturbadora. Alves (2005) também discute esse tema e problematiza "a relação que se estabelece entre a violência das telas e o comportamento agressivo dos indivíduos" (p.107).

Diante do exposto, além desses aspectos que remetem à prática de comportamentos não desejáveis, pensamos que um ponto interessante a se considerar é a relação entre os jogos eletrônicos online e a amizade. Principalmente pelo fato de os jogos e as brincadeiras traduzirem a cultura lúdica de um grupo social (Brougère, 2002). Desse modo, não é de estranhar nem a repercussão que a informatização causou na prática das atividades lúdicas nem o fenômeno do jogo eletrônico que tem alcançado de forma intensa e 
profunda nas últimas décadas a vida da população em geral e, em especial, a vida dos adolescentes, impactando, até mesmo, as suas relações interpessoais.

Explorar e compreender como a prática de jogos online influencia o relacionamento de adolescentes, em especial no que se refere à amizade, apresenta clara relevância científica e social. Até porque a maioria dos estudos publicados em periódicos importantes sobre relacionamento não tem privilegiado a adolescência (Garcia, 2005a). Assim, o objetivo geral da presente pesquisa foi identificar a concepção de adolescentes, estudantes do Ensino Médio, quanto às características de suas amizades vinculadas à prática de jogos eletrônicos online. Mais especificamente, buscou-se identificar os jogos eletrônicos online praticados pelos adolescentes investigados, a rede de amigos vinculada à prática de jogos online e o papel dos jogos eletrônicos na constituição e na manutenção de amizades.

\section{MÉTODO}

O presente trabalho enfocou alguns aspectos do relacionamento interpessoal, em especial da amizade, entre adolescentes que praticam ou já praticaram jogos online. Os dados apresentados são basicamente de natureza descritiva, de modo que, para comparar diferenças nos percentuais entre as variáveis investigadas, foi utilizado o pacote estatístico SPSS, versão 17.0.

\section{Participantes}

Participaram deste estudo 110 adolescentes (Bee, 1997) com idades entre 14 e 18 anos $(7,5 \%=14$ anos; $56,1 \%=15$ anos; $23,4 \%=16$ anos; $11,2 \%=17$ anos; $1,9 \%=18$ anos), sendo 69 do sexo masculino $(62,7 \%)$ e 41 do feminino (37,3\%), todos matriculados no Ensino Médio de escolas da rede pública e privada de ensino, moradores dos municípios de Vila Velha $(88,2 \%)$ e Vitória $(11,8 \%)$, Espírito Santo. A coleta dos dados foi realizada em cinco diferentes escolas: duas públicas $(42,8 \%)$ e três privadas $(57,2 \%)$; e colocou-se, como condição para a participação, que os adolescentes respondentes fossem praticantes regulares ou já tivessem jogado alguma modalidade de jogo eletrônico online.

\section{Instrumento}

Os dados foram levantados a partir da aplicação de um questionário com 28 questões sobre aspectos de relacionamento interpessoal, num contexto do jogo eletrônico online. O questionário buscou abordar diferentes aspectos do relacionamento interpessoal, em especial a amizade, de modo que o conteúdo das perguntas foi pensado a partir de questões relevantes sobre a amizade na adolescência. Os itens do questionário pretenderam investigar hábitos dos participantes ao jogar e verificar se estes favorecem a formação de vinculações sociais. Para tanto, o instrumento contemplou questões para analisar aspectos tais como: contato e comunicação, intimidade e proximidade, satisfação, apoio social e compromisso. É importante ressaltar que parte das questões elaboradas para o instrumento foi baseada no trabalho de Pylro (2007).

\section{Procedimentos}

Os dados foram coletados nas próprias escolas, durante o período normal de aulas, com a ajuda de uma assistente de pesquisa. A aplicação dos questionários foi realizada de forma coletiva, sendo estabelecido um número máximo de 20 adolescentes por aplicação. Cabe ressaltar que foi firmado como condição para o início da coleta de dados que os responsáveis legais pelos participantes assinassem um Termo de Consentimento Livre e Esclarecido.

\section{RESULTADOS E DISCUSSÃO}

É fundamental deixar claro que, tendo em vista as características da amostra do presente estudo, não pretendemos generalizar os resultados obtidos. Contudo, esperamos problematizar algumas questões sobre o tema amizade e jogos online, de maneira a contribuir para o desenvolvimento da área. Julgou-se importante, antes da exploração de aspectos mais específicos vinculados à amizade, traçar um panorama dos jogos online praticados pelos adolescentes participantes do estudo, assim como o tempo que eles investem nessa atividade e o local em que desenvolvem tal prática.

Constatou-se uma diversidade de jogos mencionados pelos adolescentes, de maneira que foram citados 54 jogos online diferentes, sendo que os mais mencionados foram Counter-Strike (20,5\%), Tibia (9,0\%), Ragnarok (7,1\%), Habbo (5,1\%), MU (5,1\%) e Sinuca $(5,1 \%)$. Essa variedade reflete a gama de opções de jogos online lançados continuamente no mercado, o que confere certo dinamismo na oferta e possibilidades de escolha de jogos a serem praticados em conjunto. O jogo mais mencionado pelos adolescentes foi $\mathrm{o}$ Counter-Strike. Trata-se de um jogo que parece ser 
bastante conhecido por esse público, e que apresenta conteúdos de violência. A preferência por jogo cujo conteúdo tenha essa temática também foi verificada nos trabalhos de Griffiths e cols. (2004) e Rossetti, Kuster, Souza e Leme (2007), em que o aspecto favorito do jogo relatado pelo grupo de adolescentes investigados nos referidos estudos foi a violência.

Quanto ao tempo investido na prática do jogo percebeu-se que os participantes jogam com certa regularidade, o que demonstra o lugar que o jogo eletrônico online ocupa no dia a dia dos adolescentes que compuseram a amostra. Dessa forma, 66,1\% dos adolescentes da amostra jogam, pelo menos, duas vezes por semana; sendo que $33,94 \%$ o fazem diariamente. Com relação ao número de horas investidas na prática do jogo mencionado, os resultados indicaram que a maioria $(66,4 \%)$ joga entre uma e duas horas por dia. Este nos parece ser um tempo bastante aceitável, o que contradiz algumas discussões de que o jogo eletrônico poderia prejudicar o contato face a face, ou mesmo o investimento em outras atividades. Apesar de esse dado não ter sido aprofundado neste estudo, é possível que o jogo eletrônico online se coloque apenas como mais um recurso, portanto complementar, na condução da comunicação e das relações interpessoais, de modo que configure aspectos dialeticamente relacionados (Pylro, 2007), e não excludentes.

Quanto ao lugar em que praticam o jogo online mencionado, os espaços mais indicados foram em casa $(82,7 \%)$, e em lan house (10,9\%). Estes dados sugerem que a maioria dos adolescentes, no caso da amostra selecionada, conta com computador com acesso à Internet em sua residência.

Um fato comum no universo dos jogos eletrônicos que aponta para a formação de um grupo, ou mesmo de uma rede de amigos vinculados ao jogo, é a existência dos chamados clãs. Esses são, em geral, grupos independentes, formados por iniciativa de praticantes de um determinado jogo que tem por objetivo agregar jogadores de modo que possam obter ajuda com mais facilidade para aprimorar tal prática, tornar o jogo mais interessante, trocar informações, entre outras possibilidades. Tal situação nos remete a uma das características da amizade, que implica ajuda mútua e reciprocidade, como discutido na fundamentação teórica do presente artigo.

Consideramos também que seria interessante investigar a principal motivação para se fazer parte de um clã e até mesmo, para verificar se o interesse em formar novas amizades compareceria como uma das vantagens observadas. Primeiramente, perguntamos aos adolescentes se estes estavam vinculados a algum clã, o que nos permitiu identificar que $48,1 \%$ participavam de algum grupo vinculado ao jogo - a um clã. Entre os que afirmaram participar, 53,4\% alegaram que conheceram o clã por meio do próprio jogo (site do jogo, por exemplo); e 24,1\% por algum amigo; e que o principal critério para ser aceito em um clã é ter um bom desempenho no jogo $(61,0 \%)$. Como um segundo critério relevante, $20,4 \%$ dos adolescentes mencionaram aspectos vinculados ao relacionamento interpessoal (indicação de amigos e aprovação pelo grupo).

Quanto à origem dos amigos do clã, aproximadamente $62,1 \%$ relataram que já tinham algum contato prévio com os outros jogadores do clã; sendo que $37,9 \%$ relataram terem tido contato apenas após o ingresso no grupo. Essas informações parecem indicar que os relacionamentos compartilhados nos jogos online complementam outros contatos que ocorrem em contextos face a face. Porém também sugerem um papel do clã na constituição de novos contatos e, quem sabe, na formação de novas amizades.

Ainda quanto ao tipo de contato com os outros jogadores, 61,0\% dos adolescentes participantes do estudo relataram que os melhores amigos, com os quais partilham outros ambientes, também estão presentes no clã. Esses dados sugerem que, assim como em outros contextos, no ambiente do jogo ou do clã, há amigos mais chegados com os quais se dividem outros ambientes e atividades, reforçando a tese de que esses contextos offline e online comparecem como complementares.

As ferramentas disponibilizadas para a comunicação entre os jogadores durante o jogo (Messenger, 36,9\%; Orkut, 11,9\%; e Teamspeak, 10,0\%) e fora do ambiente do jogo (Messenger, 34,5\%; Orkut, 27,7\%; e E-mail, 10,1\%) também parecem ser importantes na manutenção dos vínculos de amizade, pois permitem discutir questões relacionadas ao jogo, mas também propiciam conversas sobre outros temas. Os adolescentes do sexo masculino mencionaram como temas de conversas online principalmente jogos, videogames, Internet, esportes, frivolidades e garotas. Já as adolescentes, indicaram frivolidades, downloads de músicas e filmes, fofocas e garotos. 
Ainda que as conversas com os outros jogadores apontem para assuntos que extrapolam situações do próprio jogo, quando se referem a temas mais íntimos, que denotam maior proximidade, $61,8 \%$ responderam que não se sentem à vontade para falar de coisas pessoais ou de segredos para os amigos do jogo, 12,7\% relataram liberdade para conversar sobre as referidas questões, e $25,5 \%$ se sentem "mais ou menos" à vontade para conversar sobre temas mais íntimos.

Porém há indicativos de que os adolescentes investigados mantêm condutas para com os companheiros de jogo que denotam certo apoio social e compromisso $(60,9 \%$ já pediram ajuda, e $73,6 \%$ já ajudaram seus companheiros de jogo, sendo que 67,62 da ajuda dispensada ou solicitada se referem a situações do próprio jogo), além de relatarem satisfação para com as amizades decorrentes do jogo $(88,9 \%)$.

Em linhas gerais, algumas propriedades básicas constituintes da amizade face a face também puderam ser observadas nos relacionamentos compartilhados em situação de jogo, como, por exemplo, a busca de ajuda e a intenção de compartilhar experiências (Berndt, 1992), o companheirismo e algum nível de intimidade (Laursen, 1996), e um número limitado de amizades.

\section{CONSIDERAÇÕES FINAIS}

De maneira geral, a presente pesquisa parece ter cumprido seu objetivo de explorar junto aos adolescentes investigados características de suas amizades vinculadas à prática de jogos online, identificando os jogos mais praticados, a rede de amigos vinculada à prática de jogos online, e o papel dos referidos jogos na constituição e na manutenção de amizades. Inicialmente tínhamos a hipótese de que o número de horas investidas no jogo seria maior, tendo em vista que a participação em um clã configura certo compromisso com o grupo na manutenção de um bom desempenho. Porém isso não se confirmou neste estudo. Essa questão necessita ser mais bem investigada, até porque não desconsideramos a possibilidade de os adolescentes terem indicado um número de horas inferior ao que de fato se dedicam à prática dos jogos eletrônicos.

Conforme já mencionado, utilizamos como critério para a participação no estudo o adolescente praticar ou ter praticado algum jogo online. Tal exigência acabou por configurar a amostra com uma maioria de meni- nos. Tal fato sugere a necessidade de estudos que se ocupem em problematizar possíveis relações entre questões de gênero, jogos eletrônicos online, e a formação de amizades.

Há pesquisas que indicam que os participantes, em geral, já se conhecem de outros ambientes - fora do jogo. O presente estudo corrobora essa perspectiva, de maneira que, apesar de o jogo online favorecer a constituição de novas amizades, o que foi reconhecido pelos próprios participantes, comparece também como espaço de aproximação entre amigos que já compartilham amizades originadas em outros ambientes. Portanto o jogo online, assim como outras atividades que envolvem relacionamento interpessoal no contexto da Internet, parece complementar as relações de amizades (Nicolaci-da-Costa, 1998; Romão-Dias, 2001; Peris, Gimeno, Pinazo, Ortet, Carrero, Sanchiz, \& Ibanez, 2002; Suler, 2005).

Contudo vale observar que, em alguns casos, o ambiente online pode ser o eliciador de uma nova amizade. Cabe, portanto, atentarmos para o fato de que as novas tecnologias, como, por exemplo, as que viabilizam o contato e a comunicação por meio de jogos online, possibilitam outras perspectivas de relacionamento, que refletem demandadas contemporâneas. Tais contextos podem inclusive suscitar novas formas de relacionamento. Não é incomum verificarmos casos em que os contatos sociais e interpessoais se constituem inicialmente em um nível estritamente virtual ou online, expandindo-se, em um segundo momento, para outros ambientes, inclusive o pessoal. Assim como nos demais ambientes, a amizade no contexto do jogo online parece organizar-se em torno do apoio social, de modo que o tipo de apoio sofre variações em função da configuração do ambiente em que a amizade se desenvolve.

Por se tratar de um estudo exploratório, a presente investigação pôde oferecer apenas uma aproximação a um fenômeno pouco explorado, a saber, as relações de amizade entre adolescentes em um ambiente de jogos online. Portanto são necessários outros estudos mais aprofundados que ampliem essa discussão, tendo em vista que o fenômeno do jogo eletrônico online parece ter vindo para ficar, e que os próprios adolescentes $(85,3 \%)$ acreditam ser possível constituir novas amizades a partir do jogo online. 


\section{REFERÊNCIAS}

Adams, G., \& Plaut, V. C. (2003). The cultural grounding of personal relationship: Friendship in North America and West African worlds. Personal Relationship, 10, 333-347.

Alves, L. R. G. (2005). Game over: Jogos eletrônicos e violência. São Paulo: Futura.

Auhagen, A. E. (1996). Adult friendship. Em: A. E. Auhagen \& M. Von Salisch (Orgs.), The diversity of human relationships (pp. 229-247). Cambridge: Cambridge University Press.

Azmitia, M., Lippman, D., \& Ittel, A. (1999). On the relation of personal experience to early adolescents reasoning about best friendship deterioration. Social Development, 8, 275-291.

Bee, H. (1997). O ciclo vital (R. Garcez, Trad.). Porto Alegre: Artes Médicas.

Berndt, T. J. (1992). Friendship and friend's influence in adolescents. Current Directions in Psychological Science, 1, 156-159.

Brougère, G. (2002). A criança e a cultura lúdica. Em T. M. Kishimoto (Org.), O Brincar e suas teorias (pp. 19-32). São Paulo: Pioneira.

Enomoto, J. (1999). Socio-emotional development of friendship among adolescents: Activities with friends and the feeling for friends. Japanese Journal of Educational Psychology, 47, 180190.

Feld, S., \& Carter, W. C. (1998). Foci of activity as changing contexts for friendship. Em R. G. Adams \& G. Allan (Orgs.), Placing friendship in context (pp. 136-152). Cambridge: Cambridge University Press.

Ferreira, B. E. S., \& Garcia, A. (2008). Aspectos da amizade de adolescentes portadores de diabetes e câncer. Estudos de Psicologia (Campinas), 25, 293-301.

French, D. C., Rianasari, M., Pidada, S., Nelwan, P., \& Buhrmester, D. (2001). Social support of Indonesian and U.S. children and adolescents by family members and friends. Merrill Palmer Quarterly, 47, 377-394.

French, D. C., Bae, A., Pidada, S., \& Lee, O. (2006). Friendships of Indonesian, South Korean and U.S. college students. Personal Relationships, 13, 69-81.

Fonzi, A., Schneider, B. H., Tani, F., \& Tomada, G. (1997). Predicting children's friendship status from their dyadic interaction in structured situations of potential conflict. Child Development, 68, 496-506.

Garcia, A. (2005a). Relacionamento interpessoal: Uma área de investigação. Em A. Garcia (Org.), Relacionamento interpessoal: Olhares diversos (pp. 7-27). Vitória: GM Gráfica e Editora; Programa de Pós-Graduação em Psicologia da UFES.

Garcia, A. (2005b). Psicologia da amizade na infância: Uma revisão crítica da literatura recente. Interação em Psicologia, 9, 285-294.

Garcia, A. (2006). Friendship in childhood and adolescence: A study in Brazil. Em A. Garcia (Org.), Personal relationships: International studies (pp. 128-141). Vitória: UFES - Núcleo Interdisciplinar para o Estudo do Relacionamento Interpessoal.

Greco, P., Pendley, J. S., McDonell, K., \& Reeves, G. (2001). A peer group intervention for adolescents with type 1 diabetes and their best friends. Journal of Pediatric Psychology, 26, 485-490.

Griffiths, M. (1997). Friendship and social development in children and adolescents: The impact of electronic technology. Educational and Child Psychology, 13, 25-37.
Griffiths, M. D., Davies, N. O., \& Chappell, D. (2004). Online computer gaming: A comparison of adolescent and adult gamers. Journal of Adolescence, 27, 87-96.

Hinde, R. A. (1997). The self, interactions, and relationships. Em R. A. Hinde (Org.), Relationships: A dialectical perspective (pp. 23-48). Hove, UK: Psychology Press.

Instituto Brasileiro de Geografia e Estatística (2009). PNAD 2008: Mercado de trabalho avança, rendimento mantém-se em alta, e mais domicílios têm computador com acesso à Internet. Brasília: IBGE. Retirado de http://www.ibge.gov.br/home/presidencia/ noticias/noticia_visualiza.php?id_noticia $=1455 \&$ id_pagina $=1$

Laursen, B. (1996). Closeness and conflict in adolescent peer relationships: Interdependence with friends and romantic partners. Em Bukowski, W. M., Newcomb, A. F., \& Hartup, W. W. (Orgs.), The company they keep: Friendship in childhood and adolescence (pp. 186-210). New York: Cambridge University Press.

Nicolaci-da-Costa, A. M. (1998). Na malha da rede: Os impactos intimos da internet. Rio de Janeiro: Campus.

Peris, R., Gimeno, M. A., Pinazo, D., Ortet, G., Carrero, V., Sanchiz, M., \& Ibanez, I. (2002). Online chat rooms: Virtual spaces of interaction for socially oriented people. Cyberpsychology \& Behavior, 5, 43-51.

Pylro, S. C. (2004). Atividades lúdicas entre adultos jovens: Um estudo com universitários capixabas. Dissertação de mestrado não-publicada, Universidade Federal do Espírito Santo, Vitória.

Pylro, S. C., \& Rossetti, C. B. (2005). Atividades lúdicas, gênero e vida adulta. Psico-USF, 10, 77-86.

Pylro, R. (2007). Amizade.com: Amizade e adolescência na era da Internet. Dissertação de mestrado não-publicada, Universidade Federal do Espírito Santo, Vitória.

Ray, G. E., Cohen, R., \& Secrist, M. E. (1995). Best friend networks of children across settings. Child Study Journal, 25, 169-188.

Rossetti, C. B., Kuster, P. S., Souza, M. T. C. C., \& Leme, M. I. S. (2007). Jogos eletrônicos violentos e estratégias de resolução de conflitos de jovens da cidade de Vitória. Pesquisas e Práticas Psicossociais, 2, 173-185.

Romão-Dias, D. (2001). Nossa plural realidade: Um estudo sobre a subjetividade na era da internet. Dissertação de Mestrado nãopublicada, Pontifícia Universidade Católica do Rio de Janeiro.

Singer, D. G., \& Singer, J. L. (2007). Imaginação e jogos na era eletrônica. Porto Alegre: Artmed.

Silva, D. (2002). A vida íntima das palavras: Origens e curiosidades da língua portuguesa. São Paulo: Arx.

Silva, M. M., Schoen-Ferreira, T. H., Medeiros, E., Aznar-Farias, M., \& Pedromônico, M. R. M. (2004). O adolescente e a competência social: Focando o número de amigos. Revista Brasileira de Crescimento e Desenvolvimento Humano, 14, 23-31.

SPSS for Windows - Statistical Package for the Social Sciences (Versão 17.0) [Software]. Chicago, IL: SPSS.

Suler, J. (2005). The psychology of cyberspace relationships. Retirado de http://www.enotalone.com/article/3209.html

Wolak, J., Kimberly, J., Mitchell, J., \& Finkelhor, D. (2003). Escaping or connecting? Characteristics of youth who form close online relationships. Journal of Adolescence, 26, 105-119.

Recebido: $11 / 04 / 2010$ Última revisão: 04/01/2011 Aceite final: 07/02/2011 